\title{
A case of successful reperfusion through a combination of intracoronary thrombolysis and aspiration thrombectomy in ST- segment elevation myocardial infarction associated with an ectatic coronary artery
}

Yonggu Lee ${ }^{1}$ Eunjin Kim¹', Bae Keun Kim² and Jeong-Hun Shin ${ }^{1 *}$

\begin{abstract}
Background: Large thrombus burdens in ectatic coronary arteries that remain after aspiration thrombectomy can negatively impact outcomes following percutaneous coronary interventions in patients with acute myocardial infarction.

Case presentation: A 53-year-old man presented with ST-segment elevation myocardial infarction (STEMI). Coronary angiography revealed an ectatic right coronary artery (RCA) that was completely occluded in the mid portion by a large amount of thrombus. Catheter-directed intracoronary thrombolysis with alteplase led to recovery of coronary blood flow, which multiple attempts of aspiration thrombectomy had failed to achieve. Coronary angiography 9 days later showed good blood flow and insignificant stenosis remaining in the RCA; this had completely resolved in 6 months' follow-up coronary angiography.

Conclusion: Catheter-directed intracoronary thrombolysis can be performed effectively and safely when repeat aspiration thrombectomy fails to produce satisfactory coronary reperfusion in STEMI patients with large thrombus burdens in ectatic coronary arteries.
\end{abstract}

Keywords: Myocardial infarction, Aspiration thrombectomy, Intracoronary thrombolysis, Coronary ectasia, Case report

\section{Background}

Intracoronary thrombosis in patients with ST-segment elevation myocardial infarction (STEMI) can cause distal embolization, no-reflow phenomena and stent thrombosis, and increase the risk of adverse cardiac events and death following primary percutaneous coronary interventions (PCIs) [1,2]. Although the beneficial effect of manual aspiration thrombectomy (MAT) during primary PCIs is still open to debate, it is frequently employed as a first-line therapy to reduce these adverse events [3]. However, there are no other effective options when

\footnotetext{
*Correspondence: cardio.hyapex@gmail.com

'Division of Cardiology, Department of Internal Medicine, Hanyang University Guri Hospital, 153, Gyeongchun-ro, Guri-si, Gyeonggi-do 11923, South Korea

Full list of author information is available at the end of the article
}

MAT delivers insufficient coronary blood flow, especially in patients with large thrombus burdens. Here we report a case of successful coronary reperfusion through a combination of catheter-directed intracoronary thrombolysis and MAT in STEMI caused by thrombotic occlusion of an ectatic coronary artery.

\section{Case presentation}

A 53-year-old man presented in the emergency department with sudden chest pain lasting for $30 \mathrm{~min}$. He was a 40-pack-year current smoker with high blood pressure on no medication. Blood pressure was 160/110 $\mathrm{mmHg}$ and pulse rate 60 beats $/ \mathrm{min}$. Electrocardiography showed ST-segment elevations in leads II, III, and aVF (Fig. 1a). Serum creatinine was $0.8 \mathrm{mg} / \mathrm{dl}$ and serum 


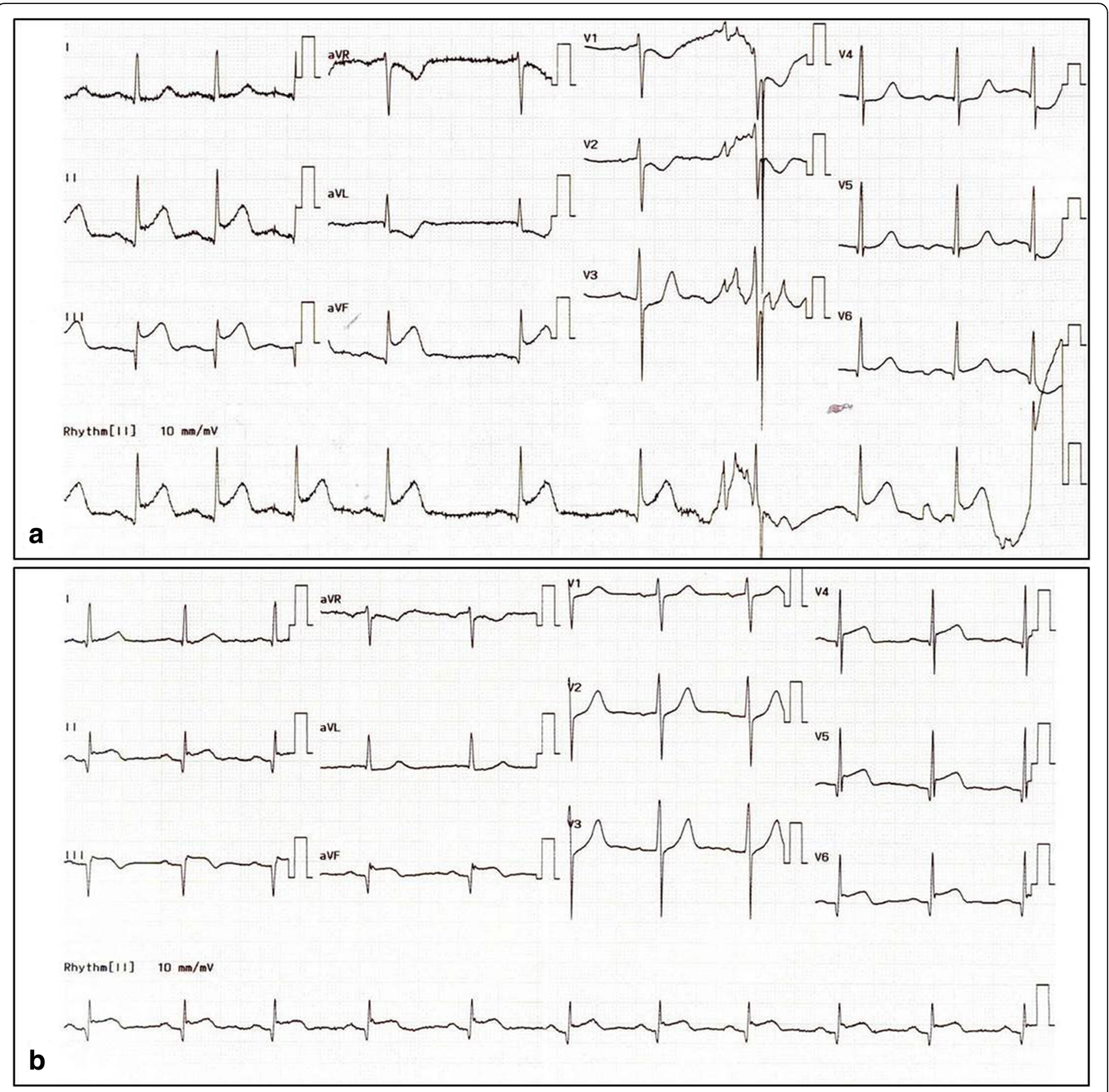

Fig. 1 Electrocardiograms. a at admission. b after percutaneous coronary intervention

troponin I $0.01 \mathrm{ng} / \mathrm{ml}$. Killip classification was class I. Aspirin $300 \mathrm{mg}$ and ticagrelor $180 \mathrm{mg}$ were administered, and coronary angiography (CAG) was performed immediately under temporary ventricular pacing. CAG revealed an ectatic right coronary artery (RCA) completely occluded by a large amount of thrombus in the mid-portion (Fig. 2a). A bolus of unfractionated heparin (8000 IU) and glycoprotein IIb/IIIa antagonist (abciximab, $0.25 \mathrm{mg} / \mathrm{kg}$ ) was administered intravenously and MAT was performed three times using a 6-Fr aspiration catheter (Rebirth, Goodman Co. Ltd., Nagoya, Japan). After red thrombi were aspirated, thrombolysis in myocardial infarction (TIMI) grade 2 flow was achieved but a large filling defect persisted in the mid portion of the RCA, with distal embolization in the posterior descending artery (PDA) (Fig. 2b). Intravascular ultrasound (IVUS) (Atlantis, Boston Scientific, Natick, MA) revealed a ruptured plaque containing a large necrotic core and a large amount of thrombus remaining in the lesion. The external elastic membrane (EEM) diameter and the luminal diameter of the normal adjacent proximal segment of the occlusion were $7.5 \mathrm{~mm}$ and $6.5 \mathrm{~mm}$, respectively (Fig. 3a). The culprit lesion was $7.7 \mathrm{~mm}$ in EEM diameter and $4.8 \mathrm{~mm}^{2}$ in minimal luminal area 

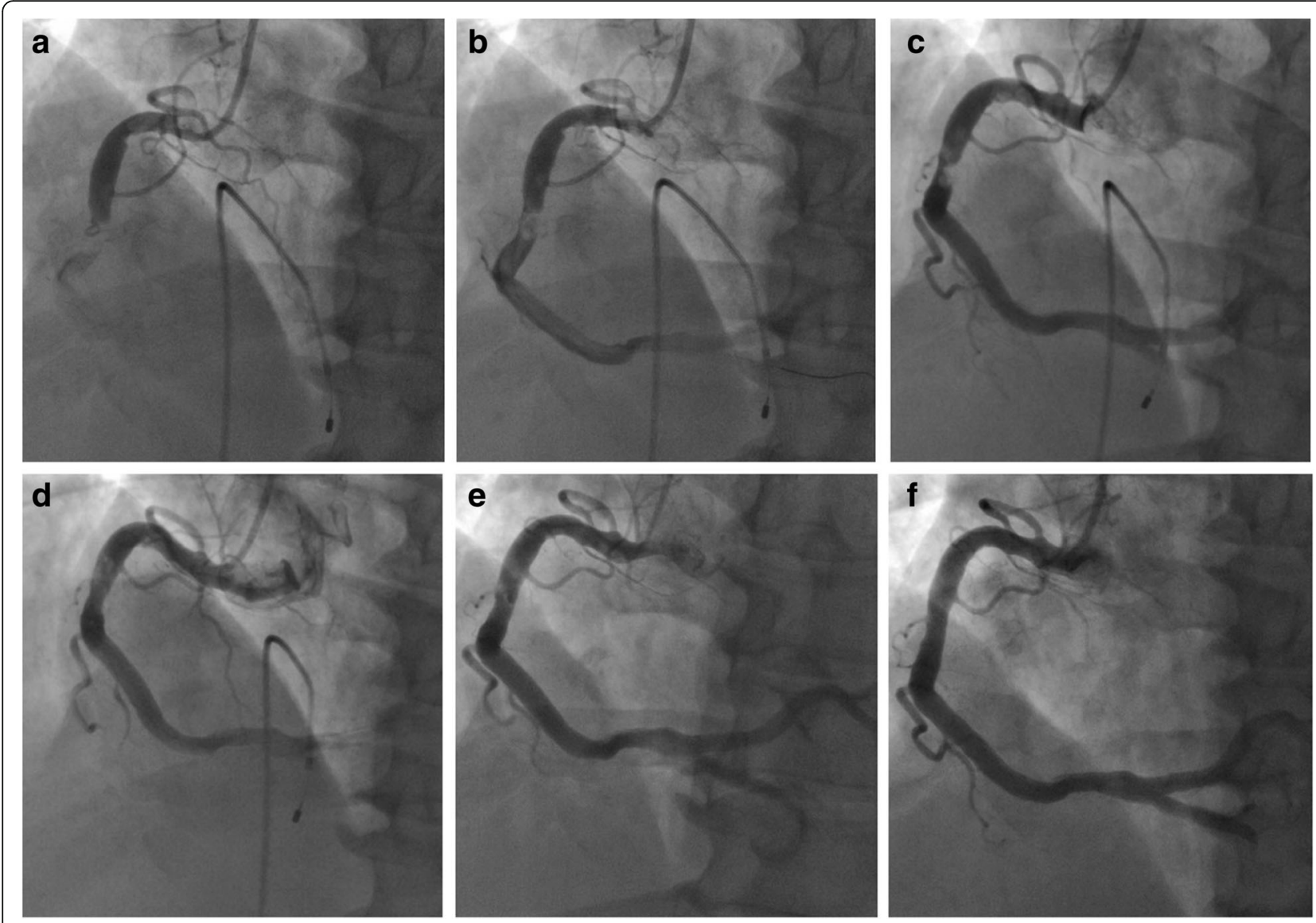

Fig. 2 Coronary angiography. a Thrombotic total occlusion of the mid portion of the right coronary artery (RCA) with TIMl grade 0 flow. $\mathbf{b}$ After thrombus aspiration, a large filling defect remained due to extensive thrombus in the mid portion of the RCA with distal embolization in the posterior descending artery (PDA). c After initial intracoronary thrombolysis and repeated thrombus aspiration, improvement of TIMI flow, distal embolization, and residual thrombus at the mid portion of the RCA were noted. $\mathbf{d}$ After balloon angioplasty and second intracoronary

thrombolysis, the culprit stenotic lesion was dilated, but TIMI flow worsened with distal embolization. e On the ninth day after the primary percutaneous intervention, TIMI flow was restored, but focal eccentric intermediate stenosis with some residual thrombus remained at the mid portion of the RCA. $\mathbf{f}$ Six months after discharge, marked dissolution of the thrombus and only minimal stenosis at the mid portion of the RCA was noted

(MLA) (Fig. 3b). Because stent apposition might be difficult in such a large vessel, we decided to perform catheter-directed intracoronary thrombolysis using alteplase. The tip of a $2.7 \mathrm{Fr}$ microcatheter (Progreat ${ }^{\circ}$, Terumo, Somerset, NJ, USA) was placed on the culprit lesion, and $5 \mathrm{mg}$ of alteplase (Actilyse, Boehringer Ingelheim, Germany) in $5 \mathrm{~mL}$ normal saline was slowly administered over five minutes through the microcatheter. After $10 \mathrm{~min}$, CAG showed improved coronary blood flow from the TIMI grade 2 to 3 in the mid portion of the RCA and from the TIMI grade 0 to 1 in the PDA, with remaining thrombi in the mid portion (Fig. 2c). Because significant stenosis persisted, a $4.5 \times 8 \mathrm{~mm}$ noncompliant balloon (Quantum, Boston Scientific, Natick, MA) was inflated up to $16 \mathrm{~atm}$ in the mid portion of the RCA to disrupt the partially lysed thrombi. The lesion was dilated after the balloon angioplasty; however TIMI flow of the RCA appeared to be worsened (Fig. 2d). Intracoronary thrombolysis was repeated in the same manner. Blood flow improved to TIMI grade 3 and IVUS showed increased MLA with remaining thrombi (Fig. 3c). The chest pain was completely relieved and the ST-segment elevation was resolved (Fig. 1b).

Intravenous infusion of the glycoprotein IIb/IIIa inhibitor was maintained for $12 \mathrm{~h}$ after PCI. Oral administration of aspirin $(100 \mathrm{mg} /$ day $)$, ticagrelor $(180 \mathrm{mg} /$ day $)$, rosuvastatin $(20 \mathrm{mg} /$ day), bisoprolol $(1.25 \mathrm{mg} /$ day $)$, and candesartan $(8 \mathrm{mg} /$ day $)$ was continued. Low molecular weight heparin (dalteparin $100 \mathrm{IU} / \mathrm{kg}$ every $12 \mathrm{~h}$; Frag$\min ^{\circ}$, Pfizer Inc., New York, NY) was administered subcutaneously after the femoral sheath was removed. No significant bleeding complications occurred after PCI. CAG repeated 9 days after the PCI revealed TIMI grade 3 blood flow in the RCA and PDA, and insignificant 


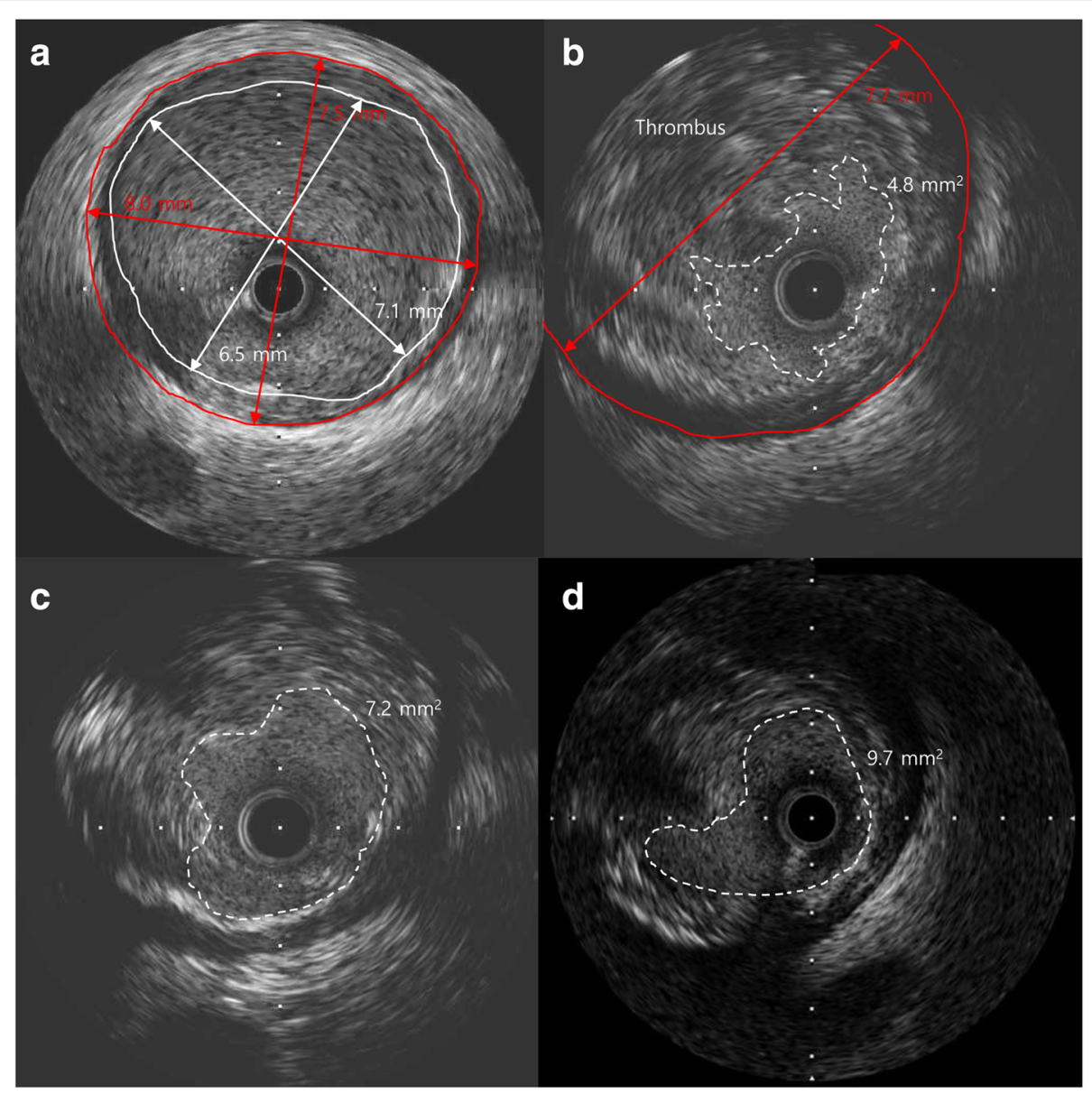

Fig. 3 Intravascular ultrasound (IVUS) findings. a Adjacent normal segment proximal to the occlusion site. The shortest EEM and luminal diameter were $7.5 \mathrm{~mm}$ and $6.5 \mathrm{~mm}$, respectively. $\mathbf{b}$ A ruptured plaque containing many necrotic components and a large amount of thrombus. The diameter of the external elastic membrane was $7.7 \mathrm{~mm}$. c After thrombus aspiration and intracoronary thrombolysis, intermediate stenosis with remnant thrombi was noted. $\mathbf{d}$ On the ninth day after the primary percutaneous intervention, a minimal lumen area of about $9.73 \mathrm{~mm}^{2}$ with plaque was noted

focal stenosis with a small amount of remaining thrombus in the lesion (Fig. 2e). IVUS showed that the MLA was $9.7 \mathrm{~mm}^{2}$ in the lesion (Fig. 3d) and the fractional flow reserve measured under maximal hyperemia was 0.98 . Based on these assessments, we decided not to perform any additional intervention. The patient was discharged 12 days after PCI. CAG repeated 6 months after PCI showed complete dissolution of the thrombi and minimal remaining stenosis in the lesion with TIMI 3 blood flow in the RCA (Fig. 2f).

\section{Discussion and conclusions}

Massive intracoronary thrombi are associated with unsuccessful angiographic reperfusion and unfavorable clinical outcomes [1, 4]. Unresolved intracoronary thrombi can cause microvascular obstruction, known as the no-reflow phenomenon, and result in reduced myocardial perfusion at the microvascular level, increased infarct size and higher mortality [5]. Although there have been improvements in antiplatelet and anticoagulant regimens and technical advances in PCIs, intracoronary thrombus remains one of the most dreaded enemies of interventional cardiologists. MAT is one of the most frequently used thrombectomy methods in primary PCIs, because the procedure is simple and the risk of vascular injury and distal embolism is low. Clinical guidelines also suggest that MAT is a reasonable approach when intracoronary thrombi are encountered [3]. However, studies have yielded inconsistent results in terms of its benefits in primary PCI [6-8]. The TASTE trial showed no benefits of MAT for mortality, re-hospitalization and stent thrombosis [8]. More recently, Jolly et al. [7] also reported that MAT did not reduce cardiovascular events, whereas it increased stroke rate. This result may partly be related to insufficient thrombus removal and inadequate coronary blood flow recovery in cases with massive intracoronary thrombosis. Safe and feasible alternative strategies are needed when MAT fails during primary PCI. 
Before coronary stents were much used, intracoronary thrombolysis was used in patients with all types of coronary artery disease $[9,10]$. However, because studies gave discouraging results [11] and primary PCI with stent implantation became routine, intracoronary thrombolysis was rarely used in clinical practice. In recent years, intracoronary thrombolysis has regained popularity as an adjuvant therapy for primary PCI, as studies using different thrombolytic agents and improved antiplatelet regimens showed it to be safe and effective. Kelly et al. [12] reported that intracoronary infusion of tenecteplase was safe and effective for coronary flow recovery in patients with myocardial infarction. More recently, Boscarelli et al. [13] found that adjuvant intracoronary infusion of low dose tenecteplase and alteplase in STEMI significantly reduced the thrombi remaining after MAT and improved coronary blood flow. Several case reports of massive intracoronary thrombosis also described successful recovery of coronary blood flow after intracoronary thrombolysis using alteplase [14] and tenecteplase [15].

We used the glycoprotein IIb/IIIa inhibitor after intracoronary thrombolysis, which may significantly increase the risk of major bleeding events. However, the thrombolytic agent doses used through intracoronary routes are usually much lower than those used through intravenous routes. Kelly et al. [12] also reported that only 1 case of major bleeding (2.9\%) among 34 patients after intracoronary thrombolysis using tenectaplase, which is similar to the major bleeding rates reported regularly in acute coronary syndrome [16]. Moreover, the majority of the patients (76\%) in their study received glycoprotein IIb/IIIa inhibitors simultaneously with intracoronary thrombolysis.

In our case, a massive thrombotic occlusion occurred in the ectatic RCA. Coronary ectasia is defined as a diffuse dilation of a coronary artery to a diameter at least 1.5 times larger than normal coronary artery diameter [17]. It is present in 1-5\% of patients undergoing CAG [18]. Various reperfusion strategies including MAT alone, simple balloon angioplasty, pulse-spray thrombolysis, intracoronary thrombolysis and mesh-covered stent implantation have been proposed in STEMI in ectatic coronary arteries [19-21]. Several randomized controlled trials have reported that rheolytic thrombectomy was more effective than MAT in thrombus removal and myocardial reperfusion in patients with STEMI, although there were no differences in infarct sizes and adverse cardiac events following PCI between rheolytic thrombolysis and MAT [22, 23]. Simple balloon angioplasty might increase the risk of distal embolization after intracoronary thrombus is incompletely removed. Prolonged intravenous heparin infusion is a viable option for the remaining thrombus after MAT in ectatic coronary arteries [24]. However, for ectatic coronary arteries, because the sheer amount of thrombus is massive and blood flow is slow, no single strategy would be sufficient. In fact, we employed multiple strategies namely MAT, balloon angioplasty and intracoronary thrombolysis during the $\mathrm{PCI}$ to achieve a good immediate result. We think that the additional anatomical and physiological information obtained by IVUS and by measuring the fractional flow reserve helped us avoid stent implantation, which could have led to incomplete stent apposition. Self-expendable stents have been introduced for patients with complex coronary anatomy including aneurysmal dilation, which may also be an alternative strategy to avoid difficulty in stent apposition, as shown in our case [25].

In conclusion, catheter-directed intracoronary thrombolysis may be a safe and effective alternative reperfusion strategy that may be selected when MAT alone fails to achieve sufficient coronary blood flow in the culprit vessel in STEMI associated with massive thrombosis in ectatic coronary arteries.

\section{Abbreviations \\ CAG: Coronary angiography; IVUS: Intravascular ultrasound; MLA: Minimal lumen area; PCl: Primary percutaneous coronary intervention; PDA: Posterior descending artery; RCA: Right coronary artery; STEMI: ST-elevation myocardial infarction; TIMI: Thrombolysis in myocardial infarction}

\section{Acknowledgements \\ No acknowledgements. \\ Funding \\ There was no funding pertaining to the manuscript. \\ Availability of data and materials \\ All information is contained within the present manuscript. \\ Authors' contributions \\ JHS drafted the manuscript and performed the angioplasty. EK drafted the manuscript and edited the figures. BKK and YL critically revised the manuscript for important intellectual content. All authors read and approved the final manuscript.}

\section{Competing interests}

The authors declare that they have no competing interests.

\section{Consent for publication}

Written informed consent was obtained from the patient for publication of this case report and any accompanying images. A copy of the written consent is available for review by the Editor of this journal.

Ethics approval and consent to participate

Not applicable.

\section{Publisher's note}

Springer Nature remains neutral with regard to jurisdictional claims in published maps and institutional affiliations

\section{Author details}

'Division of Cardiology, Department of Internal Medicine, Hanyang University Guri Hospital, 153, Gyeongchun-ro, Guri-si, Gyeonggi-do 11923, South Korea. ${ }^{2}$ Department of Cardiology, Sungae Hospital, Seoul, Republic of Korea. 
Received: 1 December 2016 Accepted: 30 March 2017 Published online: 05 April 2017

\section{References}

1. Ndrepepa G, Tiroch K, Fusaro M, Keta D, Seyfarth M, Byrne RA, Pache J, Alger P, Mehilli J, Schomig A, et al. 5-year prognostic value of no-reflow phenomenon after percutaneous coronary intervention in patients with acute myocardial infarction. J Am Coll Cardiol. 2010;55(21):2383-9.

2. Sianos G, Papafaklis MI, Daemen J, Vaina S, van Mieghem CA, van Domburg RT, Michalis LK, Serruys PW. Angiographic stent thrombosis after routine use of drug-eluting stents in ST-segment elevation myocardial infarction: the importance of thrombus burden. J Am Coll Cardiol. 2007;50(7):573-83.

3. Kushner FG, Hand M, Smith Jr SC, King 3rd SB, Anderson JL, Antman EM, Bailey SR, Bates ER, Blankenship JC, Casey Jr DE, et al. 2009 focused updates: ACC/AHA guidelines for the management of patients with ST-elevation myocardial infarction (updating the 2004 guideline and 2007 focused update) and ACC/AHA/SCAl guidelines on percutaneous coronary intervention (updating the 2005 guideline and 2007 focused update) a report of the American College of Cardiology Foundation/American Heart Association task force on practice guidelines. J Am Coll Cardiol. 2009;54(23): 2205-41.

4. Napodano M, Dariol G, Al Mamary AH, Marra MP, Tarantini G, D'Amico G, Frigo AC, Buja P, Razzolini R, lliceto S. Thrombus burden and myocardial damage during primary percutaneous coronary intervention. Am J Cardiol. 2014;113(9):1449-56.

5. Jaffe R, Dick A, Strauss BH: Prevention and treatment of microvascular obstruction-related myocardial injury and coronary no-reflow following percutaneous coronary intervention: a systematic approach. JACC Cardiovasc Interv 2010, 3(7):695-704.

6. Vlaar PJ, Svilaas T, van der Horst IC, Diercks GF, Fokkema ML, de Smet BJ, van den Heuvel AF, Anthonio RL, Jessurun GA, Tan ES, et al. Cardiac death and reinfarction after 1 year in the thrombus aspiration during Percutaneous coronary intervention in acute myocardial infarction study (TAPAS): a 1-year follow-up study. Lancet. 2008;371(9628):1915-20.

7. Jolly SS, Cairns JA, Yusuf S, Meeks B, Pogue J, Rokoss MJ, Kedev S, Thabane L, Stankovic G, Moreno R, et al. Randomized trial of primary PCl with or without routine manual thrombectomy. N Engl J Med. 2015;372(15):1389-98.

8. Frobert O, Lagerqvist B, Gudnason T, Thuesen L, Svensson R, Olivecrona GK, James SK. Thrombus aspiration in ST-elevation myocardial infarction in Scandinavia (TASTE trial). A multicenter, prospective, randomized, controlled clinical registry trial based on the Swedish angiography and angioplasty registry (SCAAR) platform. Study design and rationale. Am Heart J. 2010; 160(6):1042-8.

9. Zhu J, Liu XM, Du CJ, Zhang ZW, Qiu YQ, Gong Y, Liu JR, Hong YR, Luo ZY, Zhang Y. Diagnostic value of lesion-directed prostate biopsy under TRUS in early detection of prostate cancer. Zhonghua nan ke xue. 2009;15(5):437-40.

10. Goudreau E, DiSciascio G, Vetrovec GW, Chami Y, Kohli R, Warner M, Sabri N, Cowley MJ. Intracoronary urokinase as an adjunct to percutaneous transluminal coronary angioplasty in patients with complex coronary narrowings or angioplasty-induced complications. Am J Cardiol. 1992;69(1):57-62.

11. Simoons ML, Wijns W, Balakumaran K, Serruys PW, van den Brand M, Fioretti P, Reiber JH, Lie P, Hugenholtz PG. The effect of intracoronary thrombolysis with streptokinase on myocardial thallium distribution and left ventricular function assessed by blood-pool scintigraphy. Eur Heart J. 1982;3(5):433-40.

12. Kelly RV, Crouch E, Krumnacher H, Cohen MG, Stouffer GA. Safety of adjunctive intracoronary thrombolytic therapy during complex percutaneous coronary intervention: initial experience with intracoronary tenecteplase. Catheter Cardiovasc Interv. 2005;66(3):327-32.

13. Boscarelli D, Vaquerizo B, Miranda-Guardiola F, Arzamendi D, Tizon H, Sierra G, Delgado G, Fantuzzi A, Estrada D, Garcia-Picart J, et al. Intracoronary thrombolysis in patients with ST-segment elevation myocardial infarction presenting with massive intraluminal thrombus and failed aspiration. Eur Heart J Acute Cardiovasc care. 2014;3(3):229-36.

14. Kim JS, Kim JH, Jang HH, Lee YW, Song SG, Park JH, Chun KJ. Successful revascularization of coronary artery occluded by massive intracoronary thrombi with alteplase and percutaneous coronary intervention. J Atheroscler Thromb. 2010;17(7):768-70.

15. Gallagher S, Jain AK, Archbold RA. Intracoronary thrombolytic therapy: a treatment option for failed mechanical thrombectomy. Catheter Cardiovasc Interv. 2012;80(5):835-7.
16. Moscucci M, Fox KA, Cannon CP, Klein W, Lopez-Sendon J, Montalescot G, White K, Goldberg RJ. Predictors of major bleeding in acute coronary syndromes: the global registry of acute coronary events (GRACE). Eur Heart J. 2003;24(20):1815-23.

17. Swanton RH, Thomas ML, Coltart DJ, Jenkins BS, Webb-Peploe MM, Williams BT. Coronary artery ectasia-a variant of occlusive coronary arteriosclerosis. Br Heart J. 1978;40(4):393-400.

18. Swaye PS, Fisher LD, Litwin P, Vignola PA, Judkins MP, Kemp HG, Mudd JG, Gosselin AJ. Aneurysmal coronary artery disease. Circulation. 1983;67(1):134-8.

19. Yokokawa T, Ujiie Y, Kaneko H, Seino Y, Kijima M, Takeishi Y. Lone aspiration thrombectomy without stenting for a patient with ST-segment elevation myocardial infarction associated with coronary ectasia. Cardiovasc Interv Ther. 2014;29(4):339-43.

20. Tanabe $Y$, Itoh E, Nakagawa I, Suzuki K. Pulse-spray thrombolysis in acute myocardial infarction caused by thrombotic occlusion of an ectatic coronary artery. Circ J. 2002;66(2):207-10.

21. Linares Vicente JA, Lukic A, Ruiz Arroyo JR, Revilla Marti P, Simo Sanchez B. Combined intracoronary thrombolysis, thrombus aspiration and meshcovered stent implantation for organized massive thrombus burden in ectatic coronary. Cardiovasc Interv Ther. 2014;29(1):55-9.

22. Carrabba N, Parodi G, Maehara A, Pradella S, Migliorini A, Valenti R, Comito V, Marrani M, Rega L, Colagrande S, et al. Rheolityc thrombectomy in acute myocardial infarction: effect on microvascular obstruction, infarct size, and left ventricular remodeling. Catheter Cardiovasc Interv. 2016;87(1):E1-8.

23. Vergara R, Valenti R, Migliorini A, Parodi G, Giurlani L, Marrani M, Cantini G, Antoniucci D: Rheolytic Thrombectomy for acute myocardial infarction complicated by Cardiogenic shock. J Invasive Cardiol. 2016;28(12):E193-7.

24. lelasi A, Anzuini A. Successful management of a huge thrombus in coronary aneurysmatic dilatation after failed mechanical thrombectomy during acute myocardial infarction. J Cardiovasc Med (Hagerstown). 2014;15(1):80-1.

25. La Manna A, Geraci S, Tamburino C. A self-expandable coronary stent system to treat complex coronary stenosis complicated by poststenotic aneurysm: an optical coherence tomographic evidence-based case report. J Invasive Cardiol. 2011;23(12):E277-80.

\section{Submit your next manuscript to BioMed Central and we will help you at every step:}

- We accept pre-submission inquiries

- Our selector tool helps you to find the most relevant journal

- We provide round the clock customer support

- Convenient online submission

- Thorough peer review

- Inclusion in PubMed and all major indexing services

- Maximum visibility for your research

Submit your manuscript at www.biomedcentral.com/submit
Biomed Central 